\title{
Clinical characteristics versus human leukocyte antigen class-II DRB1 alleles profiles and fecal calprotectin level in Giardia lamblia-infected children
}

\section{Original Article}

\author{
Ayat A ElBlihy ${ }^{1}$, Ahmed Megahed ${ }^{2}$, Raefa A Atia ${ }^{1}$, Fatma A Auf ${ }^{3}$, Samar N El- \\ Beshbishi $^{1}$
}

Department of Medical Parasitology ${ }^{1}$, Pediatric Gastroenterology and Hepatology Unit, Mansoura University Children's Hospital ${ }^{2}$, and Clinical Pathology Department ${ }^{3}$, Faculty of Medicine, Mansoura University, Mansoura 35516, Egypt

\begin{abstract}
Background: Giardia lamblia is a global enteric protozoan causing giardiasis, a disease characterized by different clinical presentations ranging from loss of appetite, abdominal pain, steatorrhea, nausea, vomiting to severe malabsorption syndrome, but the majority of infected children are asymptomatic, especially in developing countries. The clinical outcome may be associated with fecal calprotectin released in the bowel in case of inflammation and human leukocyte antigen (HLA) class-II DRB1 alleles that play a crucial role in the immune system.

Objectives: To reveal any association between fecal calprotectin and the development of symptomatic or asymptomatic giardiasis. Also, to highlight the influence of HLA class-II DRB1 alleles on clinical manifestations of G. lamblia-infected children.

Subjects and Methods: The study included 160 children: 80 healthy children (control), 40 Giardiapositive children with gastrointestinal symptoms (symptomatic group), and 40 Giardia-positive children without gastrointestinal manifestations (asymptomatic group). Fecal calprotectin was measured using ELISA, and HLA class-II was typed by PCR.

Results: The commonest presentation of giardiasis was abdominal pain. Fecal calprotectin level was elevated (141.40 $\pm 67.7-183 \pm 48.21 \mu \mathrm{g} / \mathrm{gm})$ in children with giardiasis, mainly among asymptomatic group. HLA class-II DRB1*03:01 and *13:01 alleles were significantly associated with incidence of giardiasis $(P<0.0005)$. A significant association of the heterozygous allotype HLA-DRB1*03:01/03:02 was recorded with giardiasis manifestations, mainly abdominal pain $(P=0.026)$.

Conclusion: Fecal calprotectin can be used as a marker of $G$. lamblia-induced intestinal inflammation. HLA class-II DRB1*03 and DRB1*13 alleles likely underlie clinical variability of giardiasis. This association may clarify why giardiasis does not occur in significant number of children exposed to the parasite.
\end{abstract}

Keywords: children; fecal calprotectin; gastrointestinal symptoms; G. lamblia; growth parameters; HLA class-II DRB1 alleles.

Received: 11 July, 2020; Accepted: 19 August, 2020.

Corresponding Author: Samar N El-Beshbishi, Tel.: +20 1224142147, E-mail: selbeshbishi@mans.edu.eg

Print ISSN: 1687-7942, Online ISSN: 2090-2646, Vol. 13, No. 2, August, 2020.

\section{INTRODUCTION}

Giardia lamblia is the most prevalent enteric protozoan, affecting about 280 million people worldwide, with $\sim 200$ million cases afflicted in developing countries ${ }^{[1]}$. Giardiasis occurs through ingestion of cysts voided in human and animal feces. Following ingestion, cysts hatch liberating the actively replicating trophozoites which bind to the small intestinal mucosa, leading to various intestinal inflammatory changes responsible for the disease manifestations ${ }^{[2]}$. Interestingly, clinical presentations vary from asymptomatic infections to different gastrointestinal symptoms [i.e. acute or chronic steatorrhea (fatty diarrhea), abdominal pain, flatulence, nausea, vomiting, and dehydration] at variable intervals ${ }^{[3]}$. In developing countries, giardiasis contributes to $15-55 \%$ of gastroenteritis cases $^{[4]}$. Moreover, other studies reported an association between $G$. lamblia infection in children and significant weight loss and growth retardation ${ }^{[5,6]}$, which increase morbidity and mortality ${ }^{[7]}$.

It is worth noting that histopathological examination of small-bowel biopsies from some patients with giardiasis revealed significant inflammatory responses and villous atrophy, while others appeared free from any indications of bowel inflammation ${ }^{[8]}$. Giardiasis was also associated with increased neutrophils infiltrating the epithelial layer in $16 \%$ of infected patients ${ }^{[9]}$. Neutrophils play a critical role in inflammation by phagocytosing and killing the invading microorganisms; therefore, they are considered as the first line of defense against infectious diseases. Upon stimulation, they release a variety of soluble proteins such as calprotectin. 
Accordingly, calprotectin level in fecal samples is a result of neutrophils migration into the gastrointestinal tissue; thus, it can be used as a non-specific marker for neutrophils activation as well as gastrointestinal inflammation ${ }^{[10]}$. Previous studies have shown increased fecal calprotectin levels in patients with gastrointestinal parasitic infections ${ }^{[11,12]}$.

Researchers highlighted the possible role of host immune response in the broad range of giardiasis clinical manifestations ${ }^{[13,14]}$. Major histocompatibility region encodes human leukocyte antigen (HLA) that participates in antigen presentation, regulation of inflammation, complement functions, as well as innate and adaptive immune mechanisms ${ }^{[15]}$. Documented studies have recorded associations between HLA classII gene polymorphisms and development of resistance or susceptibility to several parasitic infections, as well as clinical variability ${ }^{[16,17]}$. Accordingly, El-Beshbishi et $a l^{[18]}$ compared for the first time the genotype frequencies of HLA class-II DRB1 alleles in G. lambliainfected children and in children free of any enteric pathogens. The investigators demonstrated that HLA class-II DRB1*03:01 as well as DRB1*13:01 alleles were significantly $(P<0.001)$ associated with $G$. lamblia infection, while DRB1*04:02, DRB1*10:01, DRB1*14:01 and DRB1*15:01 alleles were significantly detected in control children, suggesting the involvement of those alleles in the establishment of host immune response to G. lamblia infection ${ }^{[16]}$. However, no study has comprehensively assessed the correlation between HLA class-II alleles and the clinical spectrum of giardiasis.

The present study aims to detect the correlation between the fecal level of calprotectin and the development of symptomatic or asymptomatic giardiasis, and to evaluate the influence of HLA-DRB1 alleles on the clinical features of giardiasis in children.

\section{SUBJECTS AND METHODS}

This paired-case control study was conducted between June 2017 and August 2018 at the Department of Medical Parasitology and Clinical Pathology, Faculty of Medicine, Mansoura University, Mansoura, Egypt.

Subjects: The study included 160 children aged 2-18 years, as 80 Giardia-infected cases; 40 symptomatic from the attendants of the Gastroenterology out-patient clinics of Mansoura University Children's Hospital, Mansoura, Egypt; and 40 asymptomatic patients. According to $\mathrm{WHO}^{[19]}$, types of diarrhea were classified as follows: 1) diarrhea is considered when three or more unformed stools passed in a 24-hour period or passage of frequent stool than normal; 2) diarrheal episodes are defined as diarrheal attacks separated by at least three diarrhea free days and classified according to the duration of episodes into: acute $(<14$ days), persistent ( $\geq 14$ days but $<30$ days) and chronic
( $\geq 30$ days); 3) intermittent diarrhea means at least one diarrheal episode/month. Another 80 apparently healthy children (controls) were age- and sex-matched from the patients' visitors or neighbors. The control group included children free of gastrointestinal complaints, with negative stool samples for G. lamblia and other intestinal pathogens.

A G. lamblia positive stool sample (trophozoite and/ or cyst) was the only inclusion criteria. The exclusion criteria were detection of other intestinal parasitic, bacterial, or viral co-infections, history of autoimmune diseases (inflammatory bowel diseases), and children administered anthelmintic treatment (in the last month), or systemic corticosteroids or any other immunosuppressive therapy.

A clinical history sheet was filled for each child including: demographic data (i.e. name, age, sex and residence), gastrointestinal symptoms (i.e. diarrhea, vomiting, flatulence, and abdominal pain), symptoms of anemia (i.e. pallor and headache), and growth assessment of weight and height. Ruuska score ${ }^{[20]}$ was used for assessing severity of diarrhea, and computing duration of diarrhea, maximum number of diarrheal stools/day, vomiting duration, maximum number of vomiting/day, dehydration, and body temperature.

Collection and processing of stool samples: Three stool samples were collected from each child in a labeled plastic fecal container to be examined on the same day or stored at $-20^{\circ} \mathrm{C}$ until used at the department of Medical Parasitology (Laboratory Unit), Faculty of Medicine, Mansoura University, Egypt. Each fecal sample was examined microscopically for detection of intestinal parasites by direct saline/iodine wet smear, and by formalin ethyl acetate concentration techniques ${ }^{[21]}$. All fecal samples were also stained by modified acid fast for exclusion of Cryptosporidium spp., Cyclospora cayetanensis, and Cystoisospora belli ${ }^{[22]}$. Microbiological culturing for exclusion of Salmonellae, Shigella, and Escherichia coli was also performed. ELISAs (Ridascreen, R-biopharm, Germany) were carried out to detect adenovirus and rotavirus following the manufacturer's instructions.

All fecal samples were tested to assess level of calprotectin using quantitative ELISA assay[23], according to manufacturer's instructions (Calprest, Eurospital, Spain). A standard curve was drawn to assess fecal calprotectin concentration in samples, and results were interpreted as follows: Calprotectin level $<50 \mu \mathrm{g} / \mathrm{gm}$, negative; 50-100 $\mu \mathrm{g} / \mathrm{gm}$, border line to be repeated; while $>100 \mu \mathrm{g} / \mathrm{gm}$ was considered positive, according to manufacturer's instructions.

Collection and processing of blood samples: A $5 \mathrm{ml}$ venous blood sample was collected from each participant into an EDTA tube and then transferred to the department of Clinical Pathology (Immunology 
Unit), Faculty of Medicine, Mansoura University, Egypt, for genotyping of HLA class II-DRB1 alleles in the study groups. Genomic DNA was extracted from blood using a TIANamp Genomic DNA (TIANGEN, China). HLA class II-DRB1 alleles were identified by polymerase chain reaction (PCR) and sequence-specific oligonucleotide probes (INNO-LIPA HLA-DRB1, Innogenetics, Belgium). For genetic comparisons, all siblings were excluded from analysis, as siblings share $50 \%$ of their alleles on average.

Statistical analysis: Collected data were statistically analyzed using the statistical package for social science (SPSS) software (Version 20, USA). Qualitative data were presented in the form of number and percentage, and quantitative data were presented as mean \pm standard deviation (SD). Chi-square test and Fisher test were used to test the statistical significance. The Pearson correlation coefficient was used to measure the linear correlation between two variables. In order to maximize the statistical analysis, alleles with frequencies $\leq 10 \%$ were excluded from tests of association analysis with $G$. lamblia infection. Odds ratio (OR) and 95\% confidence interval (CI) were calculated to estimate the risk of different alleles and the magnitude of association between HLA alleles and occurrence of giardiasis. Bonferroni correction was used to correct for multiple comparisons. $P$ values less than 0.05 were considered statistically significant. Also, $P$ value was corrected by two-sided Monte Carlo (PMC) significance $(99 \% \mathrm{CI})$.

Ethical considerations: The study was approved by the review boards of the Department of Medical Parasitology, Mansoura Children's Hospital Authority, and Mansoura Faculty of Medicine-Institutional
Research Board. The study was also performed in compliance with the Code of Ethics of the World Medical Association for experimentation with humans. Written informed consent was collected from parents of the enrolled children and children aged 12 years or more. Children were referred to a physician for treatment of diarrhea and any intestinal pathogen.

\section{RESULTS}

This study included three groups of children: 40 symptomatic giardiasis cases, 40 asymptomatic giardiasis cases, and 80 healthy controls, with the common denominator of matched sex and mean age.

Clinical features of symptomatic giardiasis: In children with symptomatic giardiasis, abdominal pain was the most common manifestation in 95\% of patients, followed by diarrhea in $47.5 \%(P<0.001$ for each variable). Other symptoms associated with giardiasis included flatulence in $40 \%$ of cases $(P<0.01)$ and vomiting in $25 \%(P<0.05)$. Regarding frequency of diarrhea, 17 cases (42.5\%) had acute diarrheal attacks lasting for $<2$ weeks, and two cases (5\%) had attacks continuing for $<20$ days (persistent diarrhea). Moreover, out of the 40 symptomatic children; 23 cases $(57.5 \%)$ suffered from intermittent diarrhea all over the year. Concerning the Ruuska score of disease severity, among children with acute diarrhea; 11 cases $(27.5 \%)$ were complaining of moderate diarrheal episodes, while six cases $(15 \%)$ were suffering from severe diarrheal attacks. It is worth noting that among the 19 children experiencing diarrhea; only three cases $(7.5 \%)$ suffered from mild to moderate dehydration (Table 1).

Table 1. Clinical features of symptomatic giardiasis groups.

\begin{tabular}{|c|c|c|}
\hline Clinical presentations & $\begin{array}{c}\text { Symptomatic giardiasis } \\
\text { No. (\%) }\end{array}$ & Fisher exact tes \\
\hline $\begin{array}{l}\text { Abdominal pain (No.) } \\
\quad \text { Duration (days), mean } \pm \text { SD }\end{array}$ & $\begin{array}{l}38(95) \\
5.5 \pm 2.8\end{array}$ & $F=35.1, P<0.001$ \\
\hline $\begin{array}{l}\text { Diarrhea (No.) } \\
\text { Acute } \\
\text { Ruuska score } \\
\text { Mild } \\
\text { Moderate } \\
\text { Severe } \\
\text { Duration (days), mean } \pm \text { SD } \\
\text { Persistent } \\
\text { Chronic } \\
\text { Intermittent } \\
\text { Number of diarrheal episodes/year, mean } \pm \text { SD }\end{array}$ & $\begin{array}{c}19(47.5) \\
17(42.5) \\
0(0) \\
11(27.5) \\
6(15) \\
5.47 \pm 2.79 \\
2(5) \\
0(0) \\
23(57.5) \\
12.22 \pm 6.45\end{array}$ & $F=35.1, P<0.001$ \\
\hline Flatulence & $16(40)$ & $F=20.0, P=0.001$ \\
\hline $\begin{array}{l}\text { Vomiting } \\
\quad \text { Duration (days), mean } \pm \text { SD }\end{array}$ & $\begin{array}{c}10(25) \\
2.40 \pm 1.17\end{array}$ & $F=16.6, P=0.011$ \\
\hline Dehydration (mild to moderate) & $3(7.5)$ & $F=4.6, P=0.098$ \\
\hline Fever & $3(7.5)$ & $F=4.6, P=0.098$ \\
\hline
\end{tabular}


Comparing the average number and duration of diarrheal episodes among symptomatic children inhabiting urban and rural areas revealed that these episodes were more common with longer duration in children residing in rural areas. The highest number of 9-12 annual attacks lasting for a week were recorded in rural inhabitants (Figures 1 and 2).

Growth measures of the study groups: Growth assessment of the enrolled children was within the normal range of weight (weight for age, $\mathrm{Z}$ score) for the corresponding age. While, children infected with G. lamblia were shorter than Giardia-free children revealing statistically significant correlation $(P<0.05)$ with giardiasis, but without statistically significant difference between both giardiasis groups (Table 2).

Fecal calprotectin level and its association with giardiasis manifestations: Regarding calprotectin level, a statistically significant $(P<0.001)$ elevation in fecal calprotectin was detected among $G$. lambliainfected children compared to controls. In cases with asymptomatic giardiasis, fecal calprotectin level was higher compared to those with symptomatic giardiasis, with higher percentage of asymptomatic children (92.5\%; 37 cases) having high calprotectin level compared to children with symptomatic giardiasis (62.5\%; 25 cases) (Table 3). On the other hand, no

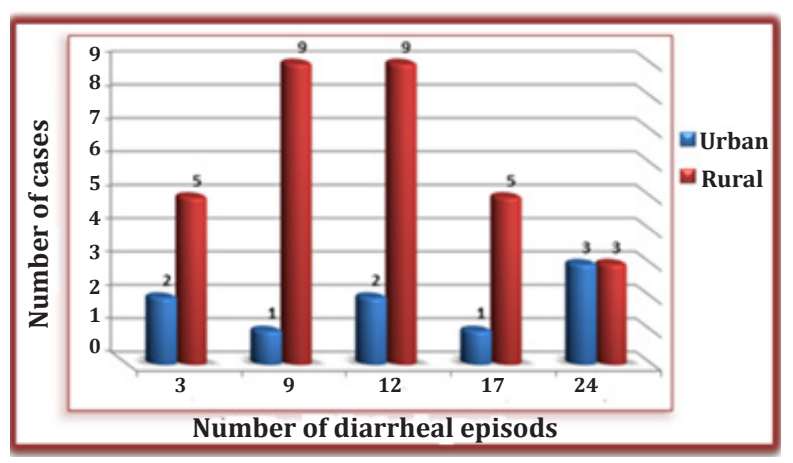

Fig. 1. Diarrheal episodes distribution for children with symptomatic giardiasis living in rural and urban areas. significant correlation was noticed between the level of fecal calprotectin and the duration or severity of diarrhea, vomiting, abdominal pain, or flatulence among cases with giardiasis (data not shown).

HLA Class-II typing and association with giardiasis manifestations: To detect whether HLA-DRB1 alleles of the enrolled children were associated with symptomatic infection, we tested children with no infection (i.e. controls), children with asymptomatic, and with symptomatic giardiasis. It is worth mentioning that HLA-DRB1*03 allele was the most common allele shared in both symptomatic and asymptomatic giardiasis representing 32.5\% (26 alleles) and 36.25\% (29 alleles), respectively, with a statistically significant difference between giardiasis cases and controls $(P<0.005)$. HLA-DRB ${ }^{*} 13$ was the second most frequent allele $(16.25 \%, 13$ alleles) among children with symptomatic and asymptomatic giardiasis, with significant correlation $(P=0.005)$ with $G$. lamblia infection (Table 4).

In depth analysis revealed that, HLA-DRB1*03:01 allele was the most common risky allele among the different HLA-DRB1*03 alleles (44/55 alleles) detected in children with giardiasis $(P<0.0005)$. Also, a statistically significant difference was detected between symptomatic and asymptomatic giardiasis



Fig. 2. Duration of diarrheal episodes for children with symptomatic giardiasis living in urban and rural areas.

Table 2. Growth assessment of the study groups.

\begin{tabular}{|c|c|c|c|c|}
\hline Variables & $\begin{array}{c}\text { Symptomatic giardiasis } \\
(\text { No. }=40) \\
\text { Mean } \pm \text { SD }\end{array}$ & $\begin{array}{c}\text { Asymptomatic giardiasis } \\
(\text { No. }=40) \\
\text { Mean } \pm \text { SD }\end{array}$ & $\begin{array}{l}\text { Control } \\
(\text { No. }=80) \\
\text { Mean } \pm \text { SD }\end{array}$ & $P$ of One-way ANOVA- $F$ tes \\
\hline $\begin{array}{l}\text { Age (years) } \\
\text { Weight }(\mathrm{Kg}) \\
\text { Height }(\mathrm{cm})\end{array}$ & $\begin{array}{c}7.81 \pm 3.9 \\
26.3 \pm 11.45 \\
118.5 \pm 20.81\end{array}$ & $\begin{array}{c}8.7 \pm 3.43 \\
28.85 \pm 12.58 \\
125.1 \pm 19.67\end{array}$ & $\begin{array}{c}10.15 \pm 1.4 \\
33.3 \pm 17.5 \\
133.0 \pm 22.0\end{array}$ & $\begin{array}{c}0.73 \\
0.162 \\
0.031\end{array}$ \\
\hline Height (cm) & No. (\%) & & No. $(\%)$ & $\begin{array}{c}P \text { of Chi square test } \\
\text { Weight for age, } Z \text { score }\end{array}$ \\
\hline $\begin{array}{l}\text { Normal } \\
\text { Underweight } \\
\text { Overweight }\end{array}$ & $\begin{array}{c}35(87.5) \\
3(7.5) \\
2(5)\end{array}$ & \multicolumn{2}{|c|}{$\begin{array}{l}37(92.5) \\
2(5) \\
1(2.5)\end{array}$} & 0.74 \\
\hline Overweight & & & & Height for age, $\mathrm{Z}$ score \\
\hline $\begin{array}{l}\text { Not stunted } \\
\text { Stunted }\end{array}$ & $\begin{array}{l}27(67.5) \\
13(32.5)\end{array}$ & \multicolumn{2}{|c|}{$\begin{array}{l}32(80) \\
8(20)\end{array}$} & 0.201 \\
\hline
\end{tabular}


PARASITOLOGISTS UNITED JOURNAL

Table 3. Fecal calprotectin level among the study groups.

\begin{tabular}{|c|c|c|c|c|}
\hline $\begin{array}{c}\text { Fecal } \\
\text { calprotectin } \\
\text { level }(\mu \mathrm{g} / \mathrm{gm})\end{array}$ & $\begin{array}{l}\text { Symptomatic giardiasis } \\
(\text { No. }=40) \\
\text { Mean } \pm \text { SD }\end{array}$ & $\begin{array}{c}\text { Asymptomatic giardiasis } \\
(\text { No. }=40) \\
\text { Mean } \pm \text { SD }\end{array}$ & $\begin{array}{c}\text { Control } \\
(\text { No. }=80) \\
\text { Mean } \pm \text { SD }\end{array}$ & Bonferroni test \\
\hline & $\begin{array}{c}141.4 \pm 67.7 \\
P<0.001^{*} \\
P=0.002^{* *}\end{array}$ & $\begin{array}{l}183.0 \pm 48.21 \\
P<0.001 * * *\end{array}$ & $29.29 \pm 14.1$ & $\begin{array}{l}F=56.12 \\
P<0.001\end{array}$ \\
\hline & No. (\%) & \multicolumn{2}{|c|}{ No. (\%) } & No. (\%) \\
\hline Negative & $0(0)$ & \multicolumn{2}{|c|}{$0(0)$} & $60(75)$ \\
\hline Borderline & 15 (37.5) & \multicolumn{2}{|c|}{$3(7.50)$} & $20(25)$ \\
\hline Positive & $25(62.5)$ & \multicolumn{2}{|c|}{$37(92.50)$} & $0(0)$ \\
\hline
\end{tabular}

SD: standard deviation. No: number, values between parentheses refer to percentages. Variables with $P<0.05$ are in red.

$*$ Significant difference from asymptomatic group, ${ }^{* *}$ Significant difference from control group, ${ }^{* * *}$ Significant difference from control group.

cases concerning this allele $(P=0.012)$. Moreover, HLADRB1*13:01 allele was the most frequent allele out of the HLA-DRB1*13 alleles (15/26 alleles) identified in Giardia-infected children only $(\mathrm{P}<0.0005)$, without any significant difference between symptomatic and asymptomatic giardiasis (Table 5).

Frequency of HLA-DRB1*03:01 allotypes in giardiasis cases: The different HLA-DRB $1 * 03: 01$ alleles were also detailed for homozygosity or heterozygosity of allotypes to identify allotype/s associated with the presence or absence of symptoms in giardiasis cases.
Results highlighted that children with asymptomatic giardiasis did not carry HLA-DRB1*03:01/03:02 allotype, however a significant correlation $(P=0.026)$ to symptomatic giardiasis was detected; suggesting that this allotype may be associated with giardiasis manifestations. While other HLA-DRB1*03:01 allotypes did not significantly correlate with symptomatic or asymptomatic infection (Table 6).

Association of HLA-DRB1*03 alleles with giardiasis clinical manifestations: The riskiest alleles, HLADRB ${ }^{*} 03$, were correlated with the commonest

Table 4: Frequency and association of HLA-DRB1 alleles with Giardia lamblia infection among symptomatic and asymptomatic children.

\begin{tabular}{|c|c|c|c|c|c|}
\hline $\begin{array}{l}\text { HLA-DRB1 } \\
\text { alleles }\end{array}$ & $\begin{array}{c}\text { Symptomatic giardiasis } \\
\text { No. (\%) }\end{array}$ & $\begin{array}{c}\text { Asymptomatic giardiasis } \\
\text { No. (\%) }\end{array}$ & $\begin{array}{l}\text { Control } \\
\text { No. (\%) } \\
\end{array}$ & $\begin{array}{l}\text { Odds ratio } \\
(95 \% \mathrm{CI})\end{array}$ & $\begin{array}{c}\text { Chi-square test } \\
\left(X^{2}\right)\end{array}$ \\
\hline 01 & $3(3.75)$ & $3(3.75)$ & $12(7.5)$ & $0.48(0.16-1.42)$ & $\begin{array}{c}X^{2}=2.12, P^{\mathrm{MC}}=0.394 \\
(0.381-0.406)\end{array}$ \\
\hline 03 & $26(32.5)$ & $29(36.25)$ & $4(2.5)$ & $20.93(6.8-68.7)$ & $\begin{aligned} X^{2} & =54.4, P^{\mathrm{MC}}<0.0005, \\
( & <0.0005-<0.0005)\end{aligned}$ \\
\hline 04 & $8(10)$ & $8(10)$ & $32(20)$ & $4.3(0.22-0.86)$ & $\begin{aligned} X^{2}= & 6.27, P^{\mathrm{MC}}=0.047 \\
& (0.041-0.052)\end{aligned}$ \\
\hline 07 & $5(6.25)$ & $8(10)$ & $20(12.5)$ & $0.62(0.28-1.36)$ & $\begin{aligned} X^{2}= & 2.26, P^{\mathrm{MC}}=0.344 \\
& (0.331-0.356)\end{aligned}$ \\
\hline 08 & $8(10)$ & $0(0)$ & $8(5)$ & $1(0.17-7.49)$ & $\begin{aligned} X^{2}= & 8.42, P^{\mathrm{MC}}=0.016 \\
& (0.012-0.019)\end{aligned}$ \\
\hline 09 & $3(3.75)$ & $3(3.75)$ & $4(2.5)$ & $1.54(0.38-6.64)$ & $\begin{aligned} X^{2}= & 0.41, P^{\mathrm{MC}}=0.843 \\
& (0.833-0.852)\end{aligned}$ \\
\hline 10 & $0(0)$ & $0(0)$ & $16(10)$ & $0(0.0-0.0)$ & $\begin{aligned} X^{2}= & 16.8, P^{\mathrm{MC}}<0.0005 \\
& (<0.0005-0.001)\end{aligned}$ \\
\hline 11 & $11.0(13.75)$ & $5(6.25)$ & $12(7.5)$ & $1.37(0.59-3.21)$ & $\begin{aligned} X^{2}= & 3.44, P^{\mathrm{MC}}=0.190 \\
& (0.180-0.201)\end{aligned}$ \\
\hline 12 & $0(0)$ & $3(3.75)$ & $0(0)$ & $0(0.0-0.0)$ & $\begin{aligned} X^{2}= & 9.08, P^{\mathrm{MC}}=\mathbf{0 . 0 2 7} \\
& (\mathbf{0 . 0 2 2}-\mathbf{0 . 0 3 1 )}\end{aligned}$ \\
\hline 13 & 13 (16.25) & $13(16.25)$ & $8(5)$ & $3.2(1.32-8.0)$ & $\begin{aligned} X^{2}= & 10.66, P^{\mathrm{MC}}=0.005, \\
& (0.003-0.007)\end{aligned}$ \\
\hline 14 & $3(3.75)$ & $3(3.75)$ & $24(15)$ & $0.29(0.09-0.87)$ & $\begin{aligned} X^{2}= & 11.9, P^{\mathrm{MC}}=\mathbf{0 . 0 0 3} \\
& (\mathbf{0 . 0 0 2 - 0 . 0 0 5 )}\end{aligned}$ \\
\hline 15 & $0(0)$ & $5(6.25)$ & $16(10)$ & $0.27(0.05-1.35)$ & $\begin{aligned} X^{2}= & 8.7, P^{\mathrm{MC}}=\mathbf{0 . 0 1 3} \\
& (\mathbf{0 . 0 1 0 - 0 . 0 1 6 )}\end{aligned}$ \\
\hline 16 & $0(0)$ & $0(0)$ & $4(2.50)$ & $0(0.0-0.0)$ & $\begin{aligned} X^{2}= & 4.05, P^{\mathrm{MC}}=0.187 \\
& (0.176-0.197)\end{aligned}$ \\
\hline Total & 80 (100) & 80 (100) & $160(100)$ & & \\
\hline
\end{tabular}


clinical presentations in symptomatic giardiasis cases. Most children (96.1\%) who carried HLA-DRB1*03 alleles complained of abdominal pain that significantly correlated with $G$. lamblia infection $(P<0.001)$. Out of the 26 HLA-DRB $1 * 03$, only 5 alleles were associated with diarrhea, 2 alleles were correlated with vomiting, and 11 alleles with flatulence in symptomatic giardiasis patients, without any significant relation to G. lamblia infection. Furthermore, the most frequent HLADRB1*03 allotype (03:01/03:02) was associated with abdominal pain in all symptomatic children (Table 7).

Table 5. Association between the most frequently identified HLA-DRB1 alleles and symptomatic or asymptomatic G. lamblia infection.

\begin{tabular}{|c|c|c|c|c|c|}
\hline $\begin{array}{l}\text { HLA-DRB1 } \\
\text { alleles }\end{array}$ & $\begin{array}{c}\text { Symptomatic giardiasis } \\
\text { No. (\%) } \\
\end{array}$ & $\begin{array}{c}\text { Asymptomatic giardiasis } \\
\text { No. (\%) }\end{array}$ & $\begin{array}{l}\text { Control } \\
\text { No. (\%) } \\
\end{array}$ & $\begin{array}{c}\text { Odds ratio } \\
(95 \% \mathrm{CI})\end{array}$ & $\begin{array}{l}\text { Chi-square test } \\
\qquad\left(X^{2}\right)\end{array}$ \\
\hline \multirow{3}{*}{ 03:01 } & $18(22.5)$ & $26(32.5)$ & $4(2.5)$ & 21 & $X^{2}=42.353$ \\
\hline & $P=0.001 *$ & $P<0.001 *$ & & $(6.54-74.80)$ & $P^{\mathrm{MC}}<0.0005$ \\
\hline & $P=0.012^{* *}$ & & & & $(<0.0005-0.0005)$ \\
\hline \multirow{3}{*}{ 13:01 } & $10(12.5)$ & $5(6.25)$ & $0(0)$ & 2.33 & $X^{2}=19.235$ \\
\hline & $P<0.001^{*}$ & $P=0.002 *$ & & $(2.23-8.95)$ & $P^{\mathrm{MC}}<0.0005$ \\
\hline & $P=0.15^{* *}$ & & & & $(<0.0005-0.0005)$ \\
\hline \multirow{3}{*}{ 04:02 } & $3(3.75)$ & $0(0)$ & $16(10)$ & 0.16 & $X^{2}=10.463$ \\
\hline & $P=0.003^{*}$ & $P=0.002 *$ & & $(0.03-0.60)$ & $P^{\mathrm{MC}}=0.004$ \\
\hline & $P=0.08^{* *}$ & & & & $(0.002-0.006)$ \\
\hline \multirow{3}{*}{ 10:01 } & $0(0)$ & $0(0)$ & $16(10)$ & 0 & $X^{2}=16.8$ \\
\hline & $P<0.001 *$ & $P<0.001 *$ & & $(0.0-0.0)$ & $P^{\mathrm{MC}}<0.0005$ \\
\hline & & & & & $(<0.0005-0.0005)$ \\
\hline \multirow{3}{*}{ 14:01 } & $3(3.75)$ & $3(3.75)$ & $24(15)$ & 0.19 & $X^{2}=11.917$ \\
\hline & $P=0.004^{*}$ & $P=0.004 *$ & & $(0.04-0.79)$ & $P^{\mathrm{MC}}=0.003$ \\
\hline & $P=0.099^{* *}$ & & & & $(0.001-0.004)$ \\
\hline \multirow{3}{*}{$15: 01$} & $0(0)$ & $3(3.75)$ & $16(10)$ & 0.12 & $X^{2}=10.463$ \\
\hline & $P=0.002 *$ & $P<0.001 *$ & & $(0.02-0.52)$ & $P^{\mathrm{MC}}=0.004$ \\
\hline & $P=0.077^{* *}$ & & & & $(0.002-0.006)$ \\
\hline
\end{tabular}

No: number. $\boldsymbol{P}^{\mathrm{MC}}$ : $P$ value by two-sided Monte Carlo significance $(99 \% \mathrm{CI})$. Values between parentheses refer to percentages. Data presented are numbers and percentages of HLA-DRB1 alleles. Variables with $P<0.05$ are in red. *Statistical difference from control, ${ }^{* *}$ Statistical difference from asymptomatic giardiasis.

Table 6. Frequency of HLA-DRB1*03:01 and HLA-DRB1*13:01 allotypes among giardiasis cases.

\begin{tabular}{lccc}
\hline \hline HLA-DRB1 alleles & $\begin{array}{c}\text { Symptomatic giardiasis } \\
\text { No. (\%) }\end{array}$ & $\begin{array}{c}\text { Asymptomatic giardiasis } \\
\text { No. (\%) }\end{array}$ & Chi-square test $\left(X^{2}\right)$ \\
\hline 03:01/03:01 & $3(7.5)$ & $3(7.5)$ & $X^{2}=0.000, P^{\mathrm{MC}}=1.000$ \\
03:01/03:02 & $6(15)$ & $0(0)$ & $X^{2}=6.486, P^{\mathrm{MC}}=\mathbf{0 . 0 2 6}$ \\
$\mathbf{0 3 : 0 1 / 0 3 : 0 5}$ & $0(0)$ & $3(7.5)$ & $X^{2}=3.117, P^{\mathrm{MC}}=0.241$ \\
$\mathbf{0 3 : 0 1 / 1 3 : 0 3}$ & $0(0)$ & $3(7.5)$ & $X^{2}=3.117, P^{\mathrm{MC}}=0.241$ \\
03:01/13:50 & $0(0)$ & $3(7.5)$ & $X^{2}=3.117, P^{\mathrm{MC}}=0.241$ \\
03:01/14:01 & $3(7.5)$ & $3(7.5)$ & $X^{2}=0.000, P^{\mathrm{MC}}=1.000$ \\
\hline \hline
\end{tabular}

No: number, $\boldsymbol{P}^{\mathrm{Mc}}$ : $P$ value by two-sided Monte Carlo significant $(99 \% \mathrm{CI})$. Values between parentheses refer to percentages. Data presented are numbers and percentages of HLA-DRB1 alleles. Variables with $P<0.05$ are in red.

Table 7. Frequency of clinical symptoms associated with HLA- DRB1*03 allele/allotypes among symptomatic giardiasis cases.

\begin{tabular}{|c|c|c|c|c|}
\hline HLA-DRB1* 03 allele & $\begin{array}{c}\text { Abdominal pain } \\
\text { No. (\%) } \\
\end{array}$ & $\begin{array}{c}\text { Diarrhea } \\
\text { No. (\%) } \\
\end{array}$ & $\begin{array}{c}\text { Vomiting } \\
\text { No. (\%) } \\
\end{array}$ & $\begin{array}{c}\text { Flatulence } \\
\text { No. (\%) } \\
\end{array}$ \\
\hline No & $1(3.9)$ & $21(80.7)$ & $24(92.3)$ & 15 (57.7) \\
\hline Yes & $25(96.1)$ & 5 (19.3) & $2(7.7)$ & $11(42.3)$ \\
\hline Chi-Square test & $X^{2}=20.91, P<0.001$ & $X^{2}=0.70, P=0.40$ & $X^{2}=0.25, P=0.61$ & $X^{2}=0.09, P=0.93$ \\
\hline \multicolumn{5}{|l|}{ HLA-DRB1* 03 allotypes } \\
\hline 03:01/03:02 & $6(100)$ & $0(0)$ & $0(0)$ & $3(50)$ \\
\hline
\end{tabular}




\section{DISCUSSION}

G. lamblia is responsible for a great proportion of diarrheal outbreaks all over the world and for travelers' diarrhea. It is related to serious episodes of diarrheal diseases, which are the commonest cause of the overall mortality and morbidity after pulmonary diseases ${ }^{[24]}$.

Giardiasis most often occurs in developing countries due to inadequate sanitation and insufficient water treatment, causing a wide spectrum of clinical presentations ${ }^{[3]}$. Accordingly, the present study attempted to estimate the clinical outcomes of giardiasis among Egyptian children. The results revealed that the most common complaint of symptomatic cases was abdominal pain, followed by diarrhea, flatulence and then vomiting, with statistically significant association $(P<0.05)$ with giardiasis. The results corroborate with a previous study on Egyptian children that revealed a significant association $(P=0.0001)$ between $G$. lamblia infection and the development of abdominal pain, flatulence and diarrhea ${ }^{[25]}$, but differs from El-Badry et $a .^{[26]}$ results which revealed that abdominal cramps are the commonest manifestation (36.1\%) followed by vomiting (19.4\%), then flatulence and diarrhea $(13.9 \%)$.

Among the studied children, the diarrheal attacks were acute or intermittent rather than being persistent, while no chronic attacks were recorded. Contrarily, Ismail et $a .^{[25]}$, reported a statistically significant association between Giardia parasites and persistent diarrhea, while no association was revealed with intermittent diarrhea. In the current study, the intensity of acute diarrheal attacks was moderate to severe, they were repeated up to $12.22 \pm 6.45$ times/ year and were more frequent at the age of 2-5 years. This may be attributed to the fact that protection against diarrheal attacks is consistent with the development of host immune resistance. Moreover, record of the most common 9 and 12 episodes revealed higher incidence with longer duration (7 days) in rural than urban residents. The children's age in addition to their increased outdoor activities and water consumption mostly from untreated water supplies, as well as close contact with farm animals may be the reasons for the frequency and duration of these diarrheal attacks.

The consequence of giardiasis on host nutrition is variable, but it is mostly associated with retarded growth $^{[27]}$, and delayed weight gain ${ }^{[28]}$. Accordingly, our analysis of the growth parameters revealed that $26.25 \%$ of infected children had stunted growth (shorter height) with statistically significant correlation $(P<0.05)$ with giardiasis. This finding agrees with the concept that acquirement of infection below 2 years old has an impact on the child's height ${ }^{[29]}$. However, 90\% of giardiasis cases had normal weight compared with their corresponding ages, which could be explained by the absence of chronic diarrhea that is usually associated with weight loss.

The use of fecal calprotectin as associate marker for clinical severity in cases of gastrointestinal infections is widely recognized nowadays. To the best of our knowledge, no previous study correlated the level of fecal calprotectin with the different clinical manifestations of giardiasis in children. Our results demonstrated that, fecal calprotectin level was significantly $(P<0.001)$ elevated to a mean of $162.4 \pm 57.95 \mu \mathrm{g} / \mathrm{gm}$ in $G$. lamblia-infected children, however, its level was not as high as in inflammatory bowel diseases. The present study data are in harmony with previous studies that reported elevated fecal calprotectin level in Giardia-infected children ${ }^{[10,30]}$. Increased fecal calprotectin reflects a mild degree of small bowel inflammation mainly of neutrophil type because of giardiasis in children. Moreover, increased fecal calprotectin level was more prominent among asymptomatic cases $(92.5 \%)$ than symptomatic ones $(62.5 \%)$, which could be related to the ability of Giardia to modulate host immune response through decreasing intestinal inflammatory markers ${ }^{[31]}$. It was suggested that low grade intestinal inflammation is probably a predisposing factor for the advancement of post-infection irritable bowel syndrome ${ }^{[32]}$, which is characterized by persistent mucosal infiltration of immune cells as neutrophils ${ }^{[33]}$. Controversially fecal calprotectin elevation was not significantly associated with the frequency or duration of different clinical manifestations in G. lamblia-infected children.

The distinction in giardiasis presentations is referred to several factors, among which the host immune response attracted attention of researchers ${ }^{[13,14]}$. Studies have linked the genetic polymorphism of HLA with clinical spectrum of some enteric protozoal infections ${ }^{[34,35]}$. Moreover, Grit et al. ${ }^{[36]}$ noticed increased expression of HLA class-II molecules on the surface of bovine dendritic cells incubated with Giardia trophozoites. The HLA class-II alleles present foreign antigens processed into short peptides to CD4+T cells, while in most of class-II processing places in B-cells, macrophages and dendritic cells, only a single allele is fitted for conferring diverse thousand peptides to a CD4+ $\mathrm{T}$ cell ${ }^{[37]}$. The peptide-binding groove of HLA class-II molecule is open-ended and can harbor peptides longer than those presented by class-I alleles, therefore it is thought that polymorphisms occur mainly in the antigen-binding groove and affect HLA-II specificity as binding receptors ${ }^{[38]}$.

The most important finding of our study is the demonstration that HLA class-II DRB1 alleles impact the clinical manifestations of giardiasis. The study revealed that Egyptian Giardia-infected children were more frequently carrying the HLA class-II DRB1*03: 01 or $* 13: 01$ alleles. So, we suggest that these alleles 
may be responsible for improper antigen presentation and/or HLA-CD4 ${ }^{+}$T-cell interaction and subsequent development of insufficient host immune resistance as well as greater host susceptibility to giardiasis.

Additionally, our study supports that HLADRB1*03:01/03:02 could play a role in susceptibility to clinical burden of giardiasis; as a significant correlation $(P=0.026)$ was detected between this allotype and the emergence of giardiasis clinical manifestations, mainly abdominal pain. It is noteworthy that abdominal cramps occurring in the course of the disease are due to T-cell-mast cell interaction that promotes release of mast cell granules and subsequent intestinal smooth muscle contractility ${ }^{[39]}$. Hence, this result reflects that HLA-DRB1*03:01/03:02 may influence $\mathrm{T}$ cells regulation.

In support of the linkage of host genetics to susceptibility and clinical presentations for some intestinal protozoal infections are the previous observations of a link between the HLA haplotype DQB1*06:01/DRB1*15:01 and delayed onset of Entamoeba histolytica infection ${ }^{[34]}$. Moreover, a significant correlation between HLA class-II DQB1*03:01 and asymptomatic Cryptosporidium infection in children, as well as DQB1*03:01/ DRB1*11:01 haplotype with both symptomatic and asymptomatic cryptosporidiosis was previously demonstrated $^{[35]}$.

Conclusively, the present study revealed that fecal calprotectin level was elevated in G. lamblia-infected children, mainly amongst asymptomatic children, indicating the possibly that giardiasis induces a degree of enteric inflammation mainly of neutrophil type. Consequently, the increased fecal calprotectin may be considered an early marker for the incidence of post-infection irritable bowel syndrome. The most important findings are the significant associations of HLA class-II DRB1*03:01 allele with giardiasis, and the heterozygous allotype HLA-DRB $1 * 03: 01 / 03: 02$ with the development of clinical manifestations of giardiasis mainly abdominal pain.

Limitations of the study: This study has some limitations. The number of children recruited was small to adequately address the research aim. The immunological status of children as well as Giardia genotypes were not detected. A large-scale study could fill the gaps.

Acknowledgement: Deepest gratitude to our colleagues at the Department of Medical Microbiology, Faculty of Medicine, Mansoura University for their help in microbiological culture as well as adenovirus- and rotavirus- ELISA.

Authors contribution: ElBlihy AA was responsible for methodology, data acquisition, analysis, and interpretation, helped in drafting the work and approved the final version to be published; Megahed A clinically examined the cases, supervised and revised the work critically for important intellectual content, and approved the final version to be published; Atia RA shared the supervision, reviewed and approved the final version to be published; Auf FA helped in methodology, supervision, revised the work critically for important intellectual content and approved the final version to be published; El-Beshbishi SN proposed the concept, supervised laboratory work and data interpretation, wrote the original draft, and critically revised it for important intellectual content.

Declaration of interest: The authors do not have any conflict of interests to disclose.

\section{REFERENCES}

1. Zylberberg HM, Green PH, Turner KO, Genta RM, Lebwohl B. Prevalence and predictors of Giardia in the United States. Dig Dis Sci 2017; 62(2):432-440.

2. Minetti C, Chalmer, RM, Beechin, NJ, Prober, C, Lamden K. Giardiasis. BMJ 2016; 355(i5369): 1-9.

3. Cotton JA, Beatty JK, Buret AG. Host-parasite interactions and pathophysiology in Giardia infections. Int J Parasitol 2011; 41(9): 925-933.

4. Alum A, Sbai B, Asaad H, Rubino JR, Khalid Ijaz M. ECCRT-PCR: a new method to determine the viability and infectivity of Giardia cysts. Int J Infect Dis 2012; 16(5): e350-e353.

5. Newman RD, Moore SR, Lima AA, Nataro JP, Guerran RL, Sears CL. A longitudinal study of Giardia lamblia infection in North-East Brazilian children. Trop Med Int Health 2001; 6:624-634.

6. Simsek Z, Zeyrek FY, Kurcer MA. Giardia infection on growth and psychomotor development of children aged 0-5 years. J Trop Ped 2004; 50:90-93.

7. Schroeder DG, Brown KH. Nutritional status as a predictor of child survival: summarizing the association and quantifying its global impact. Bull Wld Hlth Org 1994; 72(4): 569-579.

8. Troeger H, Epple HJ, Schneider T, Wahnschaffe U, Ullrich R, Burchard GD, et al. Effect of chronic Giardia lamblia infection on epithelial transport and barrier function in human duodenum. Gut 2007; 56(3): 328-335.

9. Koot BG, Ten Kate FJ, Juffrie M, Rosalina I, Taminiau JJ, Benninga MA. Does Giardia lamblia cause villous atrophy in children? a retrospective cohort study of the histological abnormalities in giardiasis. J Pediatr Gastr Nutr 2009; 49(3):304-308.

10. Hestvik E, Tumwine, JK Tylleskar T, Lena Grahnquist L, Ndeezi G, Kaddu-Mulindwa DH, et al. Faecal calprotectin concentrations in apparently healthy children aged 0-12 years in urban Kampala, Uganda, a community-based survey. BioMed Central Pediatrics 2011; 11(1): 1-9.

11. Salman YJ, Ali CA, Abdul Razaq AA. Fecal calprotectin among patients infected with some protozoan 
infections. Int J Curr Microbiol App Sci 2017; 6:32583274 .

12. Mohammad SM, Moawad HS, Sherif MM. Prevalence of intestinal protozoa among patients with inflammatory bowel disease and irritable bowel syndrome. J Egypt Soc Parasitol 2019; 49(1): 153-162.

13. Solaymani-Mohammadi SH, Singer SM. Giardia duodenalis: The double-edged sword of immune responses in giardiasis. Exp Parasitol 2010; 126(3): 292-297.

14. Cotton JA, Amat CB Buret AG. Disruptions of host immunity and inflammation by Giardia duodenalis: potential consequences for co-infections in the gastrointestinal tract. Pathogens 2015; 4:764-792.

15. Shiina T, Hosomichi K, Inoko H, Kulski JK. The HLA genomic loci map: expression, interaction, diversity, and disease. J Hum Genet 2009; 54(1): 15-39.

16. Mangano VD, Modiano D. Host genetics and parasitic infections. Clin Microbiol Infect 2014; 20: 1265-1275.

17. Shimokawa PT, Targa LS, Yamamoto L, Rodrigues JC, Kanunfre KA, Okay TS. HLA-DQA1/B1 alleles as putative susceptibility markers in congenital toxoplasmosis. Virulence 2016; 7(4): 456-464.

18. El-Beshbishi SN, ElBlihy AA, Atia RA, Megahed A, Auf FA. Human leukocyte antigen class-II DRB1 alleles and Giardia lamblia infection in children: A case-control study. Asian Pac J Trop Med 2020;13(2): 56-61

19. www.who.int/mediacentre/factsheets/fs330/en/. Diarrheal disease. Accessed 22 July 2016.

20. Lewis K. Vesikari clinical severity scoring system manual. PATH: A catalyst for Global Health 2011; Version 1.3, 1-41.

21. Truant AL, Elliott SH, Kelly MT, Smith JH. Comparison of formalin-ethyl ether sedimentation, formalin-ethyl acetate sedimentation, and zinc sulfate flotation techniques for detection of intestinal parasites. J Clin Microbiol 1981; 13(5): 882-884.

22. Casemore DP, Armstrong M, Sands RL. Laboratory diagnosis of cryptosporidiosis. J Clin Pathol 1985; 38(12): 1337-1341.

23. Coorevits L, Baert FJ, Vanpoucke HJ. Faecal calprotectin: comparative study of the Quantum Blue rapid test and an established ELISA method. Clin Chem Lab Med. 2013;51:825-831.

24. Cama VA, Mathison BA. Infections by intestinal coccidia and Giardia duodenalis. Clin Lab Med 2015; 35(2): 423-444.

25. Ismail MA, El-Akkad DM, Rizk EM, El-Askary HM, ElBadry AA. Molecular seasonality of Giardia lamblia in a cohort of Egyptian children: a circannual pattern. Parasitol Res 2016; 115(11): 4221-4227.

26. El-Badry AA, Mohammed FA, Gawad EA. Predominance of Giardia intestinalis assemblage $\mathrm{B}$ in diarrheic children in Sharkia, Egypt. PUJ 2017; 10 (1\&2):39-42.

27. Prado MDS, Cairncross S, Strina, A Barreto ML, Oliveira-Assis AM, Rego S. Asymptomatic giardiasis and growth in young children; a longitudinal study in Salvador, Brazil. Parasitology 2005; 131(1): 51-56.

28. Ignatius $\mathrm{R}$, Gahutu JB, Klotz C, Steininger C, Shyirambere $\mathrm{C}$, Lyng $\mathrm{M}$, et al. High prevalence of Giardia duodenalis assemblage $\mathrm{B}$ infection and association with underweight in Rwandan children. PloS Negl Trop Dis 2012; 6(6): e1677.

29. Rogawski ET, Bartelt LA, Platts-Mills JA, Seidman JC, Samie A, Havt A, Haque R. Determinants and impact of Giardia infection in the first 2 years of life in the MAL-ED birth cohort. J Pediat Inf Dis Soc 2017; 6(2): 153-160.

30. Sorokman TV, Sokolnyk SV, Popelyuk AV, Bezruk TO, Bezruk VV, Popelyuk NO. Giardiasis in children: Molecular genotyping, growth, and calprotectin levels. ABMU 2019; 54(3): 522-531.

31. Veenemans J, Mank T, Ottenhof M, Baidjoe A, Mbugi, $\mathrm{EV}$, Demir AY, et al. Protection against diarrhea associated with Giardia intestinalis is lost with multinutrient supplementation: a study in Tanzanian children. PLOS Neglect Trop D 2011; 5(6): e1158.

32. Spiller R, Campbell E. Post-infectious irritable bowel syndrome. Curr Opin Gastroenterol 2006; 22(1): 1317.

33. Ibarra C, Herrera V, Pérez de Arce E, Gil LC, Madrid AM, Valenzuela L, Beltrán CJ. Parasitosis and irritable bowel syndrome. Revista Chilena De Infectología 2016; 33(3): 268-274

34. Duggal P, Haque R, Roy S, Mondal D, Sack RB, Farr $\mathrm{BM}$, et al. Influence of human leukocyte antigen class II alleles on susceptibility to Entamoeba histolytica infection in Bangladeshi children. J Infect Dis 2004; 189(3): 520-526.

35. Kirkpatrick BD, Haque R, Duggal P, Mondal D, Larsson C, Peterson K, et al. Association between Cryptosporidium infection and human leukocyte antigen class I and class II alleles. J Infect Dis 2008; 197(3): 474-478.

36. Grit GH, Devriendt B, van Coppernolle S, Geurden $\mathrm{T}$, Hope J, Vercruysse J, et al. Giardia duodenalis stimulates partial maturation of bovine dendritic cells associated with altered cytokine secretion and induction of T-cell proliferation. Parasite Immunol 2014; 36(4): 157-169.

37. Neefjes J, Jongsma ML, Paul P, Bakke O. Towards a systems understanding of MHC class I and MHC class II antigen presentation. Nat Rev Immunol 2011; 11(12): 823-836

38. Klein JAN, Sato A. The HLA system. N Engl J Med 2000; 343(10): 702-709.

39. Li E, Zhao A, Shea-Donohue T. Mast cell-mediated changes in smooth muscle contractility during mouse giardiasis. Infect Immun 2007; 75(9):4514-4518. 